\title{
Surgical Margins Status
}

National Cancer Institute

\section{Source}

National Cancer Institute. Surgical Margins Status. NCI Thesaurus. Code C123560.

The determination of the presence of actual or potential neoplastic tissue which has been left outside the boundary of a resected specimen within the patient. 